\title{
UMA PROPOSTA DE CONCEPÇÃO DE ESTILO FUNDADA NA LINGUÍSTICA TEXTUAL DE EUGÊNIO COSERIU
}

\section{A PROPOSAL FOR A CONCEPTION OF STYLE BASED ON EUGENIO COSERIU'S TEXTUAL LINGUISTICS}

\author{
Clemilton Lopes Pinheiro \\ Universidade Federal do Rio Grande do Norte \\ Natal, Rio Grande do Norte, Brasil \\ Juzelly Fernandes Barreto Moreira \\ Instituto Federal de Educação, Ciência e Tecnologia do Rio Grande do Norte \\ Natal, Rio Grande do Norte, Brasil
}

RESUMO: Este trabalho, de natureza essencialmente teórica, tem como objetivo trazer à luz uma concepção de estilo a partir de uma abordagem específica dos estudos linguísticos do texto: a linguística textual coseriana. Com base nos postulados coserianos, fundamentamos nossa proposição de estilo: tratase de um fenômeno situado no nível individual da linguagem que pode ser conceptualizado como o conjunto de procedimentos que objetivam o sentido do texto.

PALAVRAS-CHAVE: Estilo; Texto; Coseriu

\begin{abstract}
This work, essentially of theoretical kind, aims to brin a conception of style into light which is situated in a specific approach of the linguistic studies of text: Coserian text linguistics. Based on these Coserian postulates, we introduce our proposition on style: it is a phenomenon situated at the individual level of language that can be conceptualized as the set of procedures that objectify the meaning of a text.
\end{abstract}

KEYWORDS: Style; Text; Coseriu 


\section{INTRODUÇÃO}

Em sua origem, a palavra estilo (do latim stilus) designava o instrumento de metal pontiagudo utilizado pelos antigos para escrever ou desenhar em tábuas enceradas. Esse termo, inicialmente empregado apenas para fazer referência a um ponteiro de ferro que funcionava como caneta, ao longo dos séculos, teve o seu sentido tão expandido que, na atualidade, é associado a múltiplos entendimentos, os quais aparecem vinculados a diferentes áreas da nossa vida.

Ao ter a sua significação ampliada, o estilo foi alçado à condição de fenômeno e, como tal, passou a ser objeto de debates. Os primeiros estudos voltados à sua investigação têm registro na Grécia antiga e adotavam uma abordagem filosófica que se dedicava a incluí-lo em discussões acerca da eficiência retórica. Dos tempos aristotélicos até a contemporaneidade, entretanto, o interesse pela compreensão do que é e de como se manifesta o estilo tem se ramificado sobremaneira e impulsionado estudos tão diversos que, ancorados na premissa saussuriana de que o ponto de vista é que cria o objeto, podemos dizer que há vários objetos "estilo" sendo investigados.

Em se tratando dos estudos linguístico-discursivos, lugar de onde falamos, a situação se repete, isto é, temos notícia de diferentes concepções de estilo, as quais aparecem associadas a perspectivas linguístico-discursivas variadas. É nesse contexto e a partir dessa constatação que encaminharemos esta pesquisa. Nossa intenção é trazer à luz uma concepção de estilo situada em uma abordagem específica dos estudos linguísticos do texto: a linguística textual coseriana. Acreditamos que o quadro postulado por Eugenio Coseriu nos dá margem para relacionar o estilo aos procedimentos textuais através dos quais surge o sentido. Será, portanto, esse o aporte teórico adotado para a nossa proposição.

Pretendemos oferecer um desenvolvimento conceitual acerca do tema, portanto, esta é uma pesquisa de natureza essencialmente teórica, que tem como objetivo discutir epistemologicamente a pertinência da inserção do conceito de estilo no nível individual da linguagem.

O trabalho apresenta-se compartimentado em duas partes. Primeiramente, fazemos uma breve apresentação do quadro epistemológico proposto por Eugenio Coseriu sobre a linguagem, seus níveis autônomos e os princípios gerais que movimentam a engrenagem da sua teoria. Concentraremos nossa atenção no nível individual da linguagem, onde, segundo o autor, está situada a "verdadeira" e "própria" linguística do texto. Na sequência, expomos nossa proposta, qual seja: o estilo é um fenômeno situado no nível individual da linguagem que pode ser conceptualizado como o conjunto de procedimentos que objetivam o sentido do texto.

\section{A LINGUÍSTICA DE TEXTO POSTULADA POR EUGENIO COSERIU}

Em "O homem e sua linguagem", Eugenio Coseriu discute sobre a essência da linguagem, a qual, do seu ponto de vista, é fundamental para a 
definição do homem e deve ser entendida como energéia, isto é, como atividade criadora. Nesse sentido, argumenta que "a linguagem não é, em primeiro lugar, emprego, mas criação de significados e, portanto, não é tampouco simplesmente produção de signos materiais para significações já dadas, e sim criação de conteúdo e expressão ao mesmo tempo" (COSERIU, 1987, p. 26). Além disso, para o autor, a linguagem é um sistema de produção capaz de transformar os significados (os quais são tidos como conteúdos da consciência) em conteúdos de signos acessíveis por meio da fixação do conhecimento de maneira objetiva.

De forma específica, é importante salientar a informação de que a linguagem é criação de conteúdo e expressão ao mesmo tempo, pois a utilização do termo ao mesmo tempo remete a uma espécie de fusão entre o conteúdo e $a$ expressão e que é a atuação simultânea desses dois elementos que possibilita a manifestação da linguagem. A respeito de como se dão essas relações, Coseriu explica resumidamente:

No nível universal, a linguagem, considerada como atividade, é o falar (em geral), não determinado historicamente; considerada do ângulo da técnica, é o "saber falar em geral" (saber elocucional); e considerada como produto é "o falado", a totalidade do que se disse (ou ainda do que se pode dizer, sempre que se considere como "coisa feita"). No nível individual, a linguagem como atividade é o discurso, isto é, o ato linguístico (ou a série de atos conexos) de um determinado indivíduo numa dada situação; como saber, é o saber expressivo (saber relativo à elaboração dos "discursos"); e como produto é um texto (falado ou escrito). Analogamente, no nível histórico, a linguagem como atividade é a lingua concreta, tal qual se manifesta no falar, como determinação histórica deste (p.ex., o "falar italiano", o "falar francês" etc.); e como "potencialidade" é a língua enquanto saber tradicional de uma comunidade ("saber idiomático"). (COSERIU, 1980, p. 93, grifos do autor).

Dessa explicação, conclui-se que a linguagem pode ser observada e investigada em três níveis:

1) O nível universal (o qual se refere à atividade linguística em geral).

2) O nível histórico (o qual se refere às línguas particulares).

3) O nível individual (o qual se refere ao texto como acontecimento único).

Um dos pontos fulcrais a respeito do funcionamento desses três níveis é o de que, apesar da sua atuação ocorrer simultaneamente quando alguém fala ou escreve, eles são autônomos. Sobre a inevitabilidade dessa separação, o autor esclarece o seguinte: 
[...] a distinção dos três níveis da linguagem é importante e racionalmente necessária porque a esses três níveis correspondem também três níveis de funcionalidade, três estratos do significar ou tipos de "conteúdo" linguístico: a designação, o significado e o sentido (estratos que, é obvio, nos textos se apresentam simultaneamente). (COSERIU, 1980, p. 99, grifos do autor).

O nível universal dá conta dos princípios gerais do pensar e do conhecimento sobre as coisas. Fica fora dos seus limites de atuação as investigações que se preocupam com os fenômenos específicos dos idiomas. As propriedades que pertencem ao nível universal são aquelas que englobam todas as línguas, o que "implica uma série de normas de conformidade da expressão com certas normas de 'coerência' [...] que, em princípio, são válidas para todo discurso em qualquer língua.” (COSERIU, 1987, p. 157).

Coseriu chama de designação o conteúdo do nível universal, ou seja, a referência a uma coisa ou a um estado de coisas através da qual se manifesta o saber elocucional, isto é, o saber geral que o homem tem das coisas, independente do idioma que ele fala. Em suma, o nível universal gira em torno do conhecimento que o ser humano tem das coisas e do entendimento que ele possui no que tange à realidade extralinguística. É nesse nível que podemos perceber as habilidades do saber elocucional, o qual diz respeito à coerência entre o que dizemos (ou escrevemos) e os nossos princípios gerais do pensar.

O nível histórico, por sua vez, se refere a uma língua concreta. Nesse nível, entra em cena a significação que atribuímos às palavras, justamente porque essa significação só pode ser ativada a partir do saber idiomático. É também no exercício desse saber que investigamos as regras da língua e podemos acompanhar as mudanças históricas sofridas por cada uma.

Reafirmamos, a partir do próprio Coseriu (2007), que o cerne do nível histórico é a estruturação gramatical da língua. Porém, é interessante mencionar, sempre na esteira de Coseriu, que a capacidade de lidar bem com as regras de uma determinada língua não confere, necessariamente, a destreza no tocante à produção de textos, pois essa habilidade está vinculada aos acontecimentos pertencentes ao terceiro nível da linguagem: o individual.

$\mathrm{O}$ nível individual remete ao texto como produto, como acontecimento único. Isso significa que tudo o que se diz ou se escreve, além de sua designação e seu significado (conforme já vimos) possui também um sentido, o qual não se repete, antes, é próprio de cada texto. Esse sentido é concebido como a expressão da unidade de um conteúdo superior de natureza mais complexa e requer um saber expressivo para ser efetivado (COSERIU, 2007).

Os escritos coserianos mostram que a sua compreensão sobre o que é esse "conteúdo superior de natureza mais complexa" está intimamente relacionada ao conceito de sentido. E sobre sentido, Coseriu (1993) postula o seguinte: 
O conteúdo próprio de um texto, o conteúdo a que se refere o saber expressivo é o conteúdo a que chamamos de sentido, isto é, aquilo que se diz e se entende além do significado e da designação, enquanto atitude do falante, intenção do falante, maneira própria de apresentar as coisas próprias do falante, mediante a expressão verbal como tal." (COSERIU,1993, p. 37, grifo do autor.)

Esse fragmento nos aponta que, para Coseriu, o conteúdo representa o sentido, entretanto, não se trata de um conteúdo qualquer, mas do conteúdo que é "próprio de um texto", ou o conteúdo "a que se refere o saber expressivo".

$\mathrm{O}$ saber expressivo, por seu turno, corresponde à capacidade que o indivíduo possui de estruturar os textos, fazendo conexões à sua maneira e dando a cada parte da mensagem a ênfase que julga mais apropriada. $\mathrm{O}$ conjunto de "modos de fazer" de cada pessoa resulta sempre em um texto único, isto é, dotado de um conteúdo próprio; dotado, em outras palavras, de sentido. Apenso a isso, não é demais lembrar que Coseriu situa a liberdade criadora entre as propriedades essenciais da linguagem, e que, segundo ele, é no nível individual que essa criatividade se manifesta com toda a sua força, o que decorre naturalmente da emergência do saber expressivo (LAMAS, 2010).

É preciso destacar o fato de que o sentido não é condicionado ao significado, mas atua de forma autônoma. Em função disso, ainda que sentido e significado coincidam em alguns textos, eles são objetos de estudo distintos e focalizam fenômenos diferentes.

Com base nessa característica, Coseriu (2007) postula que a linguística do texto está inserida no nível individual da linguagem, e, desse modo, constitui uma linguística que se ocupa da investigação da hermenêutica do sentido, tomando cada texto como evento único.

Sendo assim, de acordo com a concepção coseriana, a linguística do texto é, incontestavelmente, uma linguística do sentido, conforme ratifica Kabatek, ao ressaltar que "a linguística de texto coseriana é a linguística do sentido, de interpretação de um texto concreto através da análise de elementos linguísticos; é uma tarefa hermenêutica baseada numa série de ferramentas que a tornam científica." (KABATEK, 2010, p. 9).

Sobre essa tarefa hermenêutica a que se refere Kabatek, Coseriu (2007) acrescenta os seguintes detalhes: 
A tarefa da linguística do texto consiste em comprovar $e$ justificar o sentido dos textos. Isto equivale exatamente à atividade que no domínio da linguística geral recebe o nome de descrição ou descrição da língua: no domínio das línguas descrever não significa outra coisa além de comprovar as funções linguísticas e comprovar sua existência em relação a uma categoria correspondente no plano da expressão; no plano do texto, então, justificar o sentido significará atribuir o conteúdo já compreendido a uma determinada expressão, isto é, mostrar que ao significante do macrossigno corresponde no texto uma expressão específica. Neste sentido, a linguística do texto é interpretação ou hermenêutica. ${ }^{1}$ (COSERIU, 2007, p. 299, grifos do autor).

Portanto, o sentido a que Coseriu se refere é apresentado como conteúdo "próprio de um texto" exatamente porque o nível individual contempla a investigação de um conteúdo que se modifica texto a texto.

A fim de evitar mal-entendidos, convém aqui uma distinção: ao identificar o nível dos textos como "individual", Coseriu não está absolutamente fazendo referência às possibilidades múltiplas de interpretação do mesmo texto ou à subjetividade dos falantes e escreventes. $\mathrm{Na}$ verdade, a discussão coseriana não passa pelas questões que envolvem o sujeito, antes, centraliza-se no texto. Nessa perspectiva, ao falar sobre o nível individual, Coseriu não está tratando do indivíduo, mas de uma característica particular dos textos, a da não repetição. É por isso que o autor apresenta o conteúdo próprio como sendo o sentido único de cada texto.

Para sustentar a autonomia do nível dos textos em relação ao nível universal e ao nível histórico das línguas, Coseriu assinala, principalmente, o fato de que as regras da língua podem ser suspensas no texto sem provocar rejeição. Além disso, os textos são influenciados pelos universos de discurso - o que não acontece com as línguas - e que possuem tradições particulares, diferentes das tradições das línguas históricas. Portanto, os textos têm regras próprias que não devem (nem podem) ser comparadas ou confundidas com as regras da língua.

\section{UMA PROPOSTA CONCEITUAL DE ESTILO A PARTIR DA LINGUÍSTICA DO TEXTO COSERIANA}

Conforme já frisamos, a linguística do texto como ciência do nível individual do falar se ocupa, essencialmente, da explicação do sentido de cada texto, razão pela qual é designada como uma hermenêutica do sentido.

Com vistas a estabelecer uma organização para as disciplinas que tomam o texto como objeto de estudo, Coseriu reflete acerca de alguns pontos fundamentais a respeito desse tema e estabelece os conceitos centrais que

\footnotetext{
${ }^{1}$ Todas as citações originais de Coseriu (2007) estão em espanhol. Nós realizamos a tradução.
} 
norteiam sua teoria sobre os níveis de linguagem. Entre esses níveis, interessa-nos particularmente o nível individual, o qual abriga as questões sobre texto e, consequentemente, sobre sentido.

Em função dos nossos propósitos, queremos chamar a atenção para o fato de que a composição do sentido passa pela combinação de uma gama de mecanismos da qual resulta um conteúdo próprio. Nas palavras do próprio Coseriu, "o sentido surge a partir das diversas relações dos signos no texto". (COSERIU, 2007, p. 276). A partir dessa constatação, encaminharemos a nossa discussão, nos dedicando a pensar sobre como se dá a inserção do estilo na constituição do sentido, dentro da perspectiva que estamos assumindo neste trabalho.

O fio condutor da nossa reflexão é o entendimento coseriano de que o sentido não é fruto da livre interpretação do indivíduo nem de leituras meramente subjetivas. Ao contrário, o autor o define como algo objetivo, e acrescenta que essa objetivação se dá a partir da atuação do conjunto de procedimentos textuais, que é particular de cada texto.

Mesmo assim, esclarece que não há garantias de que o sentido dos textos seja sempre compreendido em sua totalidade, assim como um enunciado também pode ser mal interpretado, do ponto de vista linguístico. Sobre essa possibilidade de falha interpretativa, Coseriu explica que se trata de uma limitação empírica que deriva da constatação de que não existe uma técnica de compreensão que funcione como um algoritmo, o que há é "uma educação para a compreensão, tanto no âmbito do texto como no âmbito das línguas." (COSERIU, 2007, p. 253).

Essa "educação para a compreensão" traz em seu bojo o reconhecimento de que existem "instrumentos descritivos para a interpretação dos textos", os quais Coseriu denomina de "procedimentos para a construção do sentido" (COSERIU, 2007, p. 264). Esses procedimentos, por sua vez, são os responsáveis pela objetivação do sentido dos textos. Logo, o caminho que conduz à hermenêutica do sentido passa, necessariamente, pela identificação dos procedimentos que cada texto, de forma única e particular, possui.

Acreditamos que esse postulado nos fornece elementos suficientes para que possamos propor a figuração do estilo na movimentação dessa engrenagem textual da qual fala o autor. O que estamos querendo dizer é que, embora Coseriu não mencione o termo "estilo"2 entre os elementos que compõem a sua teoria do texto, sua explanação nos dá margem para pensar que ele está relacionado com os

\footnotetext{
${ }^{2}$ Estamos conscientes de que há alguns trabalhos de Eugênio Coseriu que tocam na temática do estilo, entre os quais citamos o artigo Los conceptos de dialecto, nivel y estilo de lengua y el sentido propio de la dialectologia (COSERIU, 1981), no qual o autor discorre sobre as variantes linguísticas diatópicas (dialeto), diastráticas (nível) e diafásicas (estilo). Entretanto, a perspectiva a partir da qual o estilo é abordado nesta e nas demais pesquisas do autor de que temos notícia não coincide com a proposta que apresentamos neste trabalho. O que estamos dizendo é que está inserida em um espaço epistemológico distinto, haja vista que estamos discutindo a possibilidade de uma conceptualização de estilo aplicada à linguística textual coseriana e é somente dentro desse recorte dos seus estudos que pretendemos dar conta do conceito de estilo.
} 
procedimentos textuais através dos quais surge o sentido. Diante dessa hipótese lançada, uma primeira pergunta que pode surgir: seria então o estilo mais um entre esses procedimentos? Cremos que não.

O estilo, para nós, não representa um procedimento em si, nem tampouco está restrito a uma classe de procedimentos de mesma ordem, algo que poderia ser chamado, por exemplo, de "procedimentos estilísticos do texto"; não se trata disso. O que estamos dizendo é que a combinação particular de procedimentos que cada texto possui, à medida que constrói o seu sentido, também revela, de forma simultânea e inerente, o seu estilo. Isso é coisa muito diferente. Contudo, não estamos alheios ao fato de que uma afirmação dessa natureza possui implicações tanto acerca da abrangência quanto da operacionalidade do objeto estilo que estamos apresentando. Antes de tratarmos de cada um desses dois aspectos, insistamos um pouco mais na compreensão do objeto que estamos tentando aqui delinear.

Ora, se tomarmos como válido que o sentido, conforme postula Coseriu (2007), refere-se ao conteúdo próprio de cada texto, julgamos que não seja despropositado supor que o estilo tenha parte na maneira como esse conteúdo é configurado e envolva-se diretamente no modus operandi desses diferentes procedimentos, que, quando atuam simultaneamente, tornam-se a expressão, como dado material, desse conteúdo classificado como "irrepetível" (COSERIU, 2007).

Sob esse prisma, podemos dizer que o estilo se comporta como um arquifenômeno, tendo em vista que, embora não seja em si mesmo nenhum dos procedimentos que compõem o texto, está atrelado a eles por uma relação de inerência, o que significa dizer, do ponto de vista da sua abrangência, que o estilo se encontra impregnado no sentido que é produzido pelo texto, de maneira que não há como captá-lo por si só. Ao invés disso, a sua manifestação é de tal forma rarefeita que investir esforços para localizá-lo ou demarcá-lo isoladamente constitui-se em uma tarefa improdutiva.

No entanto, se é assim, de que forma o estilo pode ser investigado? Como se pretende viabilizar a operacionalização analítica desse conceito? Um ponto fulcral precisa ser entendido antes de partirmos para a exemplificação de como a conceptualização de estilo é passiva de operacionalização: ao nos referirmos ao fenômeno estilo, não estamos tratando de um objeto que possua natureza ontológica, pois o estilo, da forma como queremos encará-lo, só existe nos (e pelos) procedimentos que objetivam o sentido.

Essa compreensão nos conduz à conclusão de que, para se chegar ao estilo de um texto, é necessário antes elencar os procedimentos que objetivam o sentido presentes nesse texto. Somente através da ação conjunta desses procedimentos, se torna possível reconhecer o que estamos caracterizando como estilo.

A figura 1 pode auxiliar nessa compreensão: 
Figura 1

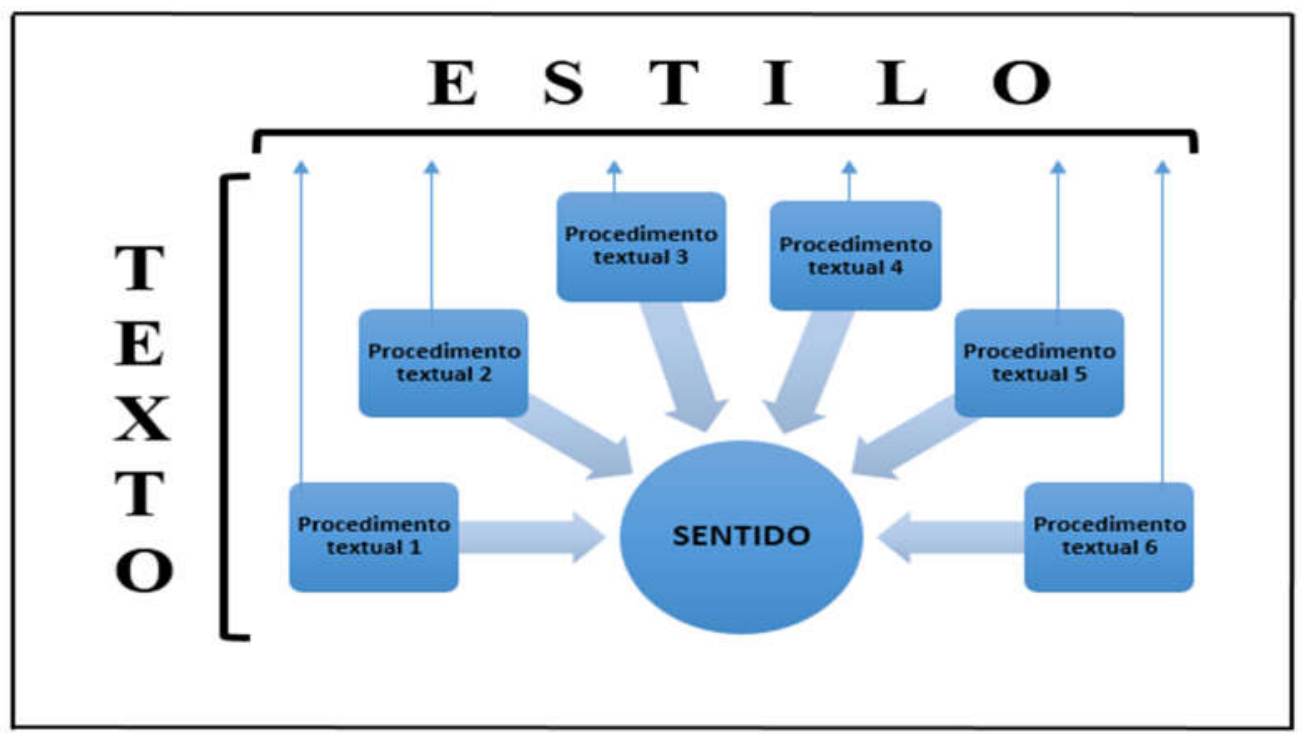

Fonte: elaborada pelos autores.

Como podemos notar, todos os procedimentos textuais ${ }^{3}$ possuem setas voltadas em direção ao sentido, o qual foi por nós posicionado no centro da figura para fazer jus ao postulado de que o sentido é objetivado pelos procedimentos textuais (COSERIU, 2007). Seguindo essa premissa, acrescentamos a esse cenário textual um outro objeto: o estilo. Como fica evidenciado no esquema, se por um lado cada procedimento contribui para a objetivação do sentido, acreditamos que, por outro lado (e ao mesmo tempo), o conjunto desses procedimentos também compõe o estilo de um texto. Diante dessa afirmação, um primeiro impulso pode ser o de imaginar que, nesse caso, sentido e estilo estão sendo aqui considerados como a mesma coisa ou como duas faces da mesma moeda. Não é bem assim.

$\mathrm{Na}$ verdade, propomos que o estilo pode ser conceituado como o conjunto de procedimentos textuais que atuam na objetivação do sentido. Logo, do nosso ponto de vista, trata-se de um objeto que não apresenta existência ontológica. Nesse sentido, só há como investigá-lo a partir da análise dos procedimentos textuais que o compõem.

Seguindo esse fio, insistimos no ponto de que o estilo, encarado como um fenômeno desprovido de existência ontológica, só pode ser configurado através da combinação desses procedimentos. Esse caráter particular, assumido pelas diferentes combinações, texto a texto, faz o sentido ser postulado como único. Ancorados nesse raciocínio, acreditamos que o estilo está situado no nível do texto, sendo, portanto, um fenômeno que pode ser integrado ao nível individual da linguagem.

\footnotetext{
${ }^{3}$ Com vistas a facilitar a compreensão da ideia que queremos passar, optamos por simular a presença de 6 procedimentos no esquema proposto, os quais foram identificados e numerados em ordem crescente apenas para garantir a clareza e a organização visual da figura. Isso não significa, absolutamente, que estejamos sugerindo que há um número fixo de procedimentos nos textos.
} 
Todavia, nada impede que os procedimentos se repitam. Isto é, se uma certa combinação de procedimentos for recorrente em textos de uma mesma pessoa, por exemplo, teremos aí configurado o seu estilo. O mesmo pode ocorrer, sem dúvida, com grupos de textos de uma mesma época, e teremos consequentemente aí desvelado, um estilo de época. Sobre essa reflexão, porém, uma distinção é absolutamente necessária: a de que não podemos estender a ideia da repetição dos procedimentos textuais até o conceito de sentido, pois, não obstante os mesmos procedimentos sejam empregados em textos diferentes, o sentido gerado em cada um deles ainda assim não se repetirá.

Tomemos como exemplo o conjunto de propagandas (figuras 2 a 6), as quais foram veiculadas em outdoors de todo Brasil.

Figura 2

\section{BEBEU E ESTÁ DIRIGINDO? DESCULPA A INTIMIDADE, MAS A VIÚVA É BONITA?}

Dirigir e beber é suicidio. Neste Carnaval, não brinque no trânsito. $B$ Bandeirantes

Fonte: http://www.agenciaintegra.com/trabalhos/bandeirantes-outdoors-carnaval

Figura 3

BEBEU E ESTÁ DIRIGINDO? CHIQUE, HEIN? SE 0 CARRO PEGAR FOGO, VAI SER CREMADO.

Dirigir e beber é suicídio. Neste Carnaval, não brinque no trânsito.

Bandeirantes

Fonte: http://www.agenciaintegra.com/trabalhos/bandeirantes-outdoors-carnaval/ 
Figura 4

\section{BEBEU E ESTÁ DIRIGINDO? VAI FICAR LINDO COM UMA COROA DE FLORES.}

Dirigir e beber é suicidio. Neste Carnaval, não brinque no trânsito. Bq Bandeirantes

Fonte: http://www.agenciaintegra.com/trabalhos/bandeirantes-outdoors-carnaval/

Figura 5

\section{BEBEU E ESTÁ DIRIGINDO? COISA LINDA: IGREJA LOTADA DAQUI A SETE DIAS.}

Dirigir e beber é suicídio. Neste Carnaval, não brinque no trânsito. $B$ Bandeirantes

Fonte: http://www.agenciaintegra.com/trabalhos/bandeirantes-outdoors-carnaval/

Figura 6

\section{Bebeu e está dirigindo? E aí, "Eterno" ou "Saudade" na comunidade do orkut?}

Responsabilidade no trânsito: você já tem idade pra isso. Bq Bandeirantes

Fonte: http://www.agenciaintegra.com/trabalhos/bandeirantes-outdoors-carnaval/

Todas essas propagandas foram construídas com a finalidade de conscientizar os motoristas sobre o perigo de dirigirem alcoolizados. Entretanto, o fato de terem sido elaborados cinco textos diferentes para tratar da mesma temática nos encaminha para a ideia de que, a despeito de estarem unidos por esse objetivo comum e, sem dúvida, abordarem o mesmo assunto, cada um dos anúncios carrega em si um sentido que não seria igualmente evocado por outro texto que não fosse ele mesmo.

Se esquecermos por um momento o objetivo geral dessa campanha publicitária e voltarmos nossos olhos para cada texto em particular, perceberemos claramente que, enquanto a figura 2 chama a atenção para o fato de que a esposa 
do motorista alcoolizado logo se tornará viúva, a figura 3 privilegia a sofisticação que supostamente envolve o ato de ser cremado ao invés de enterrado. A figura 4, por seu turno, dá relevo aos adornos que enfeitam o corpo estendido no caixão. Já a figura 5 remete a um ritual específico dos funerais de tradição católica, a missa de $7^{\circ}$ dia. Por fim, a figura 6 brinca com a escolha do título através do qual o defunto será homenageado via $\mathrm{Orkut}^{4}$. Apesar de estarem inseridos no mesmo universo semântico, os textos, definitivamente, não estão dizendo a mesma coisa. Sendo assim, insistimos, a cada um deles é conferido um sentido único e individual. Por outro lado, também não é difícil notar que alguns procedimentos textuais foram repetidamente empregados.

Para começar, podemos identificar, nos textos, a presença de linguagem coloquial, a qual é reforçada por expressões que representam marcas de oralidade. Esses procedimentos são instrumentos que auxiliam a objetivação da interpretação, uma vez que imprimem, no texto, um tom de conversa informal, e, por isso, criam uma "aura" de aproximação entre locutor e receptor, fato que podemos verificar em trechos como:

(1) Desculpa a intimidade, mas a viúva é bonita? (figura 2)

(2) Chique, hein? (figura 3)

(3) E aí, "Eterno" ou "Saudade" na comunidade do Orkut? (figura 6)

É importante frisar também que todos os anúncios fazem referência a ritos e procedimentos realizados no pós-morte de um indivíduo que pertence à cultura brasileira. Vejamos alguns exemplos:

(4) Se o carro pegar fogo, vai ser cremado. (figura 3)

Há, aqui, uma clara referência ao processo da cremação, o qual pode figurar (desde que o indivíduo ou a família não tenham optado por enterrar o corpo) entre os rituais que integram um funeral.

Vai ficar lindo com uma coroa de flores. (figura 4)

Em funerais, coroas de flores são comumente trazidas por parentes e amigos para expressar uma homenagem ao indivíduo que está sendo velado.

(6) Coisa linda: igreja lotada daqui a sete dias. (figura 5)

Trata-se de uma referência à missa de $7^{\circ}$ dia, rito tradicional em funerais de pessoas de religião católica.

(7) "Eterno" ou "Saudade" na comunidade do Orkut? (figura 6)

\footnotetext{
${ }^{4}$ Rede social filiada ao Google, criada em 2004.
} 
Neste caso, faz-se referência a uma prática comum entre os usuários do Orkut: criar comunidades a fim de homenagear amigos e/ou parentes após o seu falecimento.

Por fim, sublinhamos ainda que todos os anúncios iniciam com a mesma pergunta "Bebeu e está dirigindo?" e que fazem uso intenso de expressões referenciais associadas à ideia de morte (viúva, cremado, coroa de flores, eterno, saudade).

Esses procedimentos podem ser sintetizados no quadro 1 .

Quadro 1

\begin{tabular}{l}
\hline \multicolumn{1}{c}{ PROCEDIMENTOS TEXTUAIS - CAMPANHA PUBLICITÁRIA } \\
\hline linguagem coloquial \\
\hline marcas de oralidade \\
\hline expressões referenciais associadas à ideia de morte \\
\hline abertura do texto com uma pergunta \\
\hline
\end{tabular}

Fonte: elaborado pelos autores.

Compete-nos sublinhar que esse quadro contém apenas uma amostra dos procedimentos presentes nos textos da campanha. Trata-se, na verdade, de uma investida inicial através da qual tentamos reconhecer alguns procedimentos que apontam para a configuração do estilo dos textos. Sendo assim, enfatizamos que novas análises podem resultar na ampliação ou mesmo na reformulação desse quadro.

Contudo, se consideramos válida essa constatação de que há uma combinação de procedimentos que é recorrente no grupo de anúncios, então, é possível inferir não só que esse conjunto de procedimentos compõe o estilo de cada texto, mas também que essa repetição nos aponta para o estilo do autor, nesse caso, o publicitário (ou a agência de publicidade) responsável pela criação da campanha.

Sendo assim, de acordo com a discussão aqui empreendida, o estilo de cada um dos textos e, ao mesmo tempo, o estilo do conjunto desses textos pode ser definido por:

- Usar linguagem coloquial

- Empregar marcas de oralidade

- Fazer referências associadas à ideia de morte

- Abrir o texto com uma pergunta

Todavia, novamente lembramos que a recorrência dos procedimentos não significa que todos os textos dividam o mesmo sentido. É preciso ratificar que, independente de compartilharem os mesmos instrumentos de interpretação, as propagandas têm sentidos independentes. 
Acreditamos que, apesar da superficialidade, essa análise é capaz de nos indicar que, embora os conteúdos dos textos estejam integrados a um universo semântico comum (qual seja: o perigo de morte em que se envolve uma pessoa que dirige alcoolizada), há um sentido que se desdobra de maneira particular em cada texto, e que o estilo, da forma como queremos encará-lo, pode ser reconhecido a partir do conjunto de procedimentos que objetivam esse sentido.

\section{CONSIDERAÇÕES FINAIS}

Neste trabalho, discutimos uma possibilidade de conceptualização de estilo, que supomos estar hermeticamente circunscrita à linguística textual coseriana. Segundo Coseriu, a linguagem deve ser examinada a partir de três níveis autônomos. No terceiro deles, o nível individual, a linguística do texto entendida pelo autor como uma linguística do sentido - está situada. Ancorados nesse quadro, apresentamos a seguinte proposta: o estilo é um fenômeno do nível individual da linguagem que pode ser conceptualizado como o conjunto de procedimentos que objetivam o sentido do texto.

Enxergamos nesse aparato teórico uma abertura para discutir a figuração do estilo. A reflexão a respeito dessa possibilidade nos encaminhou para a conclusão de que esse fenômeno está relacionado aos procedimentos textuais através dos quais surge o sentido, não como representante de um procedimento específico ou como um nicho de procedimentos de mesma ordem, mas como o conjunto de todos os procedimentos que objetivam o sentido de um texto, atuando diligentemente na forma como esse sentido é configurado e envolvendo-se diretamente no modus operandi dos procedimentos que cada texto apresenta.

Atribuímos, assim, ao estilo a condição de arquifenômeno, tendo em vista que, embora não seja em si mesmo nenhum dos procedimentos que compõe o texto, mantém com eles uma relação de inerência. Em termos de abrangência, acreditamos que o estilo está sempre imbricado no sentido, de maneira que não há como captá-lo por si só, pois a sua manifestação é rarefeita. A indicação dessa impossibilidade nos encaminhou para o entendimento de que, ao nos referirmos a esse fenômeno, não estamos tratando de um objeto que possua natureza ontológica, pois ele só existe nos (e pelos) procedimentos que objetivam o sentido. Portanto, é a identificação dos procedimentos textuais que viabiliza a operacionalização da sua investigação.

Esperamos que as considerações teóricas ventiladas sejam encaradas como uma aplicação conceitual possível. Se por um lado não trazemos respostas fechadas, por outro lado, entendemos que o fato de levantarmos essa questão significa dar um (tímido) passo em direção ao desenvolvimento das pesquisas de estilo pelo viés da linguística do texto coseriana.

Somos também conscientes de que muitas questões fulcrais para o entendimento e a aplicabilidade da nossa proposição ficam à espera de desenvolvimento. Contudo, temos igual consciência de que o avanço da nossa discussão sobre estilo está entrelaçada à ampliação e ao aprofundamento das ideias coserianas acerca da construção do sentido. Se por um lado Coseriu 
estabelece os conceitos fundamentais que norteiam o estudo do texto, por outro lado ele não aponta os caminhos que ligam o sentido do texto aos procedimentos textuais que são responsáveis pela sua objetivação. Esperamos que essa lacuna conceitual impulsione outras pesquisas sobre as ideias postuladas pelo autor.

\section{REFERÊNCIAS}

COSERIU, E. Lições de Linguística Geral. Tradução de Evanildo Bechara. Rio de Janeiro: Ao Livro Técnico, 1980.

COSERIU, E. O homem e sua linguagem: estudos de teoria e metodologia linguística. Tradução de Carlos Alberto da Fonseca e Mário Ferreira. Rio de Janeiro: Presença, 1987.

COSERIU, E. Do sentido do ensino da língua literária. Revista do Instituto da Lingua e Literatura. Tradução de Evanildo Bechara, n.5, 1993, p. 29-47.

COSERIU, E. Linguística del texto. Introducción a la hermenéutica del sentido. Edición, anotación y estudio previo de Óscar Loureda Lamas. Madri: Arco/Libros, 2007.

KABATEK, J. "Prólogo." In: COSERIU, E.; LAMAS, O. L. Linguagem e discurso. Tradução de Cecília Ines Erthal. Curitiba: Editora da UFPR, 2010.

LAMAS, O. "de uma linguística do texto real e funcional". In: COSERIU, E.; LAMAS, O. L. Linguagem e discurso. Tradução de Cecília Ines Erthal. Curitiba: Editora a UFPR, 2010.

Clemilton Lopes Pinheiro ClemiltonPinheiro@hotmail.com

Juzelly Fernandes Barreto Moreira Juzelly@gmail.com

Recebido em: 16 fev. 2018

Aceito em: 31 mai. 2018

Publicado em: 19 ago. 2018 